\title{
Sexual Assault: Women's Voices on the Health Impacts of Not Being Believed by Police
}

\section{Jodie Murphy-Oikonen \\ Lakehead University \\ Ainsley Miller \\ Lakehead University \\ Lori Chambers \\ Lakehead University}

Karen McQueen ( $\nabla$ kmcqueen@lakeheadu.ca)

Lakehead University Shchool of Nursing https://orcid.org/0000-0001-9246-343X

\section{Research article}

Keywords: Sexual assault, not believed, unfounded, health, thematic analysis

Posted Date: October 9th, 2020

DOI: https://doi.org/10.21203/rs.3.rs-56310/v1

License: (a) (i) This work is licensed under a Creative Commons Attribution 4.0 International License. Read Full License

Version of Record: A version of this preprint was published at BMC Women's Health on May 22nd, 2021. See the published version at https://doi.org/10.1186/s12905-021-01358-6. 


\section{Abstract}

Background. Sexual assault is a prevalent crime against women with known negative effects on health. Recent media attention has identified that many sexual assault reports are not believed by police, and therefore coded as "unfounded". This is consistent with public discourse of inaccurate rape myths that indicate that some women lie about sexual assault. Whereas he actual rate of false reporting is low. Negative reporting experiences of sexual assault have been associated with re-victimization and trauma among survivors. However, little is known about the impact that being sexually assaulted and not believed by police has on a survivor's health and well-being. Thus, the purpose of this qualitative study was to explore women's experiences of not being believed by police after sexual assault and their perceived impact on health.

Results. Thematic analysis revealed three salient themes: 1) Broken Expectations, 2) Loss of Self, and 3) Cumulative Effect. Within the theme of Broken Expectations, two subthemes emerged including Loss of Trust and Re-victimization.

Conclusion. The findings highlighted that not being believed by police resulted in additional mental and social burdens beyond that of the sexual assault. Many survivors felt re-victimized at a time when they needed support, leading to maladaptive coping mechanisms. Having a better understanding of the negative health impacts is important for police, health, and social service providers who may be able to positively influence reporting experience and overall health effects.

\section{Background}

The high rate of sexual violence against women is a concerning public health issue as approximately one in three women experience sexual assault in their lifetime $(1,2)$. Sexual assault, defined as any type of forced or coerced sexual contact or behavior that happens without consent (3), violates the sexual integrity of the individual and exposes them to a variety of negative health outcomes (4). These may include, but are not limited to social, psychological, (4-7), sexual (6-8) and physical health outcomes (9-11) that may have lifelong deleterious effects on survivors.

Police response to sexual assault has been highly criticized based on a culture of victim blaming and stereotyping resulting in disbelief of sexual assault reports $(12,13)$. Rape myths also favor the belief that many women lie about assault $(14,15)$ and that rape only occurs to women who choose to live risky or chaotic lifestyles (16). Recent Canadian media identified that these societal myths are abundant in law enforcement, as a high number of sexual assault reports are not validated, and many sexual assault cases have been classified as "unfounded" (17). According to the criminal code of Canada, when a case is classified as "unfounded" by the police, it is determined that a crime neither occurred nor was it attempted in the first place (18). This contrasts with sexual assaults classified as unsubstantiated, as this classification is reserved for cases in which evidence is lacking and validation of the crime cannot be determined (18). As such, the code "unfounded" is indicative of the victim not being believed and interpreted as lying. However, a meta-analysis of 7 studies found that the rate of false reporting (e.g., lying) about sexual assaults was low (approximate $5 \%$ ) (19), which suggests that many cases may be inappropriately labelled as unfounded or not believed by police. A positive step was recently taken to remove the term "unfounded" in Canadian crime 
reporting statistics; however, the change in code does not automatically translate into increased belief of women's sexual assault reports to the police. While the term unfounded is specific to Canadian reporting, evidence exists that not being believed by police is a widespread issue and not unique to Canada $(20,21)$.

The experience of sexual assault and not being believed by police has not been explored from women's firsthand accounts. Research has identified that many sexual assault survivors have had negative reporting experiences with police that can negatively impact well-being (22). Others have reported negative experiences may lead to secondary victimization $(23)$ or trauma $(24,25)$. Given the known negative health effects that sexual assault has on survivors, coupled with the potential detrimental effects of a negative reporting experience, a better understanding of how not being believed by police impacts women's health is required. This is important for police, health, and social service providers who work with women who have been sexually assaulted, as a multidisciplinary response (26) to sexual assault is needed across the health, social, and legal sectors. The guiding principles of a multi-disciplinary approach are to ensure the survivor is safe, that their voice is heard, and that they have the autonomy to decide what they need for healing (27). Thus, the purpose of this study was to understand the health impacts for women who were sexually assaulted and not believed by the police. For our study, health was broadly defined as a state of physical, mental and social well-being (28).

\section{Methods}

A qualitative research design was used to explore the health impacts on women who were sexually assaulted and not believed by police. Phenomenology was the method of choice based on the focus of the lived experience of participants (29). The consolidated criteria for reporting qualitative research (COREQ) guidelines were used for reporting qualitative research (30).

Purposive sampling was used to recruit a sample of participants from a large geographic area in northwestern Ontario, Canada, between April $13^{\text {th }}$ to July $21^{\text {st }}, 2019$. Recruitment strategies included social media advertising (e.g., Facebook, Twitter, and Instagram) and through word of mouth from social service providers who had been informed of the research. Individuals wishing to learn more about the research study were invited to contact a member of the research team via cellular telephone or email. During the initial contact, the research process was explained and potential participants were invited to ask questions.

The eligibility criteria to participate in the study included: (a) being an English-speaking female 16 years of age or older, having experienced a sexual assault, which was reported to police, (b) self-report that the sexual assault was not believed by the police, and (c) ability to provide consent and participate in interviews within the designated study region. Participants were excluded from the research if: (a) the police laid charges and/or the perpetrator was taken to court, (b) the survivor of the sexual assault did not wish to pursue charges, or (c) the survivor self-identified that they were unsure whether a sexual assault occurred (unclear events or memories). A research assistant screened prospective participants by telephone to ensure they met the inclusion criteria for the research. A full explanation of the study, re-assessment of eligibility and informed consent and was obtained by the principal investigator or a co-investigator in-person, at the outset of the interview. Written consent was obtained for all in-person interviews. Verbal consent was obtained from the two participants who had telephone interviews as they were unable to be present to sign the consent. The 
informed consent process included the purpose of the research, risks and benefits of participation, anticipated outcomes and dissemination. All participants were informed of their rights including not answering questions, asking for clarification, requesting a break and/or ending the interview at any time. All participants were provided with a copy of the written informed consent. The consent process (written and verbal) was approved by the research ethics board.

Data collection was conducted by an all female research team and included one to two semi-structured faceto-face $(n=21)$ or telephone interviews $(n=2)$ based on participant preference. Interviews were conducted on the University campus and led primarily by the principal investigator or primary author with expertise in interviewing and qualitative methods. A second research team member was present to collect demographic data, take field notes and support the interview process. There were no other individuals present during the interview. Prior to commencement of the interview, introductions were made and the purpose and rationale for the research were outlined with the participant, allowing an opportunity for any participant questions to be addressed.

The interviews were open-ended and followed a semi-structured interview guide created for this study. The interview guide was developed from the literature and researcher expertise in relation to the purpose of the study (see Supplementary File 1). To isolate the impact of not being believed from that of the sexual assault, women were asked to describe the impact on health (if any) when their sexual assault report was not believed by the police and how that differed from the impact of the sexual assault on their health and well-being. In addition to the interviews, a demographic questionnaire was completed by participants after the interviews. The average length of the interviews was 53 minutes. A second interview occurred on two occasions when participants called back to report information that they felt was important and not included in the first interview. The research team discussed termination of interviews based on saturation of the data. A few additional interviews were conducted and included in the analysis once saturation had been achieved as they were previously scheduled interviews that were fulfilled.

Following each interview, participants were provided with an honorarium as a token of appreciation for their time. In addition, all participants were provided with a list of support services available in the community if they felt they required additional support. The university institutional research ethics board (ref \# 1466856) approved all study protocols.

To aid in the analysis, all interviews were audio recorded and transcribed verbatim. Transcripts were entered into NVIVO version 11. Colaizzi's (31) analytic method was used as a means of organizing and analyzing the data. This approach included extensive reading of transcribed data, extraction of significant phrases, a constant comparative method, and a comprehensive thematic description of the accounts of participants by three study team members (J.M-O, KM, A.M). A fourth study team member (LC) reviewed all themes and data collected within each theme to verify the findings. Discussion occurred between all $(n=4)$ research team members to ensure the interpretation of findings was accurately analyzed; no changes to the original thematic analysis were deemed necessary. Member checking was completed through email invitation to all research participants. Five participants requested to review the thematic findings. These findings were discussed via telephone with the principal investigator. The five participants confirmed the findings and did not add any further information. 


\section{Results}

Thirty-seven women expressed interest in the research. Twenty-three women met the inclusion criteria of having experienced a sexual assault, reported the assault to the police, and perceived that they were not believed by police. Participant's perceptions of police disbelief were determined by various factors such as the short duration of police report with little or no note taking, location of the interview (not at the police station), no incident numbers provided, blaming questions, lack of a thorough investigation, no follow-up on case outcomes from the police, no charges laid, and/or no return phone calls from the police. Some participants verbalized that police explicitly stated that they did not believe the woman's report. One participant provided a copy of the police report, which documented that the police did not believe her report. There were no individuals who refused to participate in the study, however, the researchers excluded fourteen transcripts from the analyses based on the exclusion criteria. Despite reviewing inclusion and exclusion criteria prior to the interview, there was evidence that emerged during a few interviews that some of the women were believed by police. In three cases police laid charges and the perpetrator went to court and in six cases the women chose not to pursue charges. Two of the sexual assaults were not reported to the police and two self-identified that they suspected but were not certain a sexual assault had occurred (e.g. they stated that "something didn't feel right", but had no recollection of a sexual assault). One participant was excluded as she unable to provide consent.

\section{Participant Characteristics}

Twenty-three women comprised the study sample with approximately half who self-identified as Caucasian $(n=12 ; 52 \%)$ or Indigenous $(n=11 ; 48 \%)$. The age of women at the time of the study ranged from 22 to 57 years of age $(M=37)$. Most women reported being single $(n=15 ; 65 \%)$, unemployed $(n=13 ; 56 \%)$, and earning an annual income less than $\$ 19,999(n=16 ; 69 \%)$. Various levels of education were reported, including partial high school $(n=6 ; 26 \%)$, high school completion $(n=1 ; 4 \%)$ college $(n=9 ; 39 \%)$, university ( $n$ $=5 ; 22 \%)$ and two not reported.

The characteristics of the sexual assault were mixed. More than half of the women $(n=15 ; 65 \%)$ reported knowing the perpetrator (intimate partner $[n=1]$, family member $[n=3]$, acquaintance/friend $[n=11]$ ) of the assault, while $8(35 \%)$ of the perpetrators were strangers. Likewise, the response to the sexual assault varied with nine (39\%) reporting that they physically resisted and/or verbally resisted the attacker $(n=11 ; 48 \%)$. Drugs and alcohol were a factor in many of the sexual assaults, with $57 \%(n=13)$ of perpetrators having consumed alcohol, nine of whom, had also used drugs. For the assaults by strangers, women were unsure whether the perpetrator had used drugs or alcohol. Among survivors, half reported ( $n=12 ; 52.2 \%)$ using substances prior to the assault. Of those, the majority used alcohol only $(n=8)$, alcohol and drugs $(n=3)$ or drugs only $(n=1)$. Three additional participants reported that they were forcibly given alcohol and/or drugs prior to the assault. Five participants $(21.7 \%)$ suspected that they were drugged by the perpetrator prior to being sexually assaulted.

The thematic analysis of the women's interviews revealed three salient themes related to the health and social impact of not being believed by the police. These included: (a) Broken Expectations, (b) Loss of Self, 
and (c) Cumulative Effect. Within the theme of Broken Expectations, two subthemes emerged including Loss of Trust and Re-victimization.

\section{Broken Expectations}

Overall, most participants described that the purpose of the police was to protect the public. They disclosed that this sense of safety and protection contributed to their sense of well-being and was disrupted during their report of sexual assault. Accordingly, when the women made their sexual assault reports to police, they believed that the police would assist and investigate. However, the participants explained that there was incongruence between what they believed would happen when they reported and what actually occurred. They described feelings of disappointment, being let down, having an additional pain, or that their sexual assault reports fell on "deaf ears". "They are supposed to be there to help you and keep you safe, and I didn't think they were doing it at all". An Indigenous participant who reported her sexual assault to the police and waited more than 24 hours for a police response, described how she thought making a report would be the first step of the healing process after the sexual assault, but believed that her experience with the police made it [sexual assault experience] all worse:

You think that they [police] are going to protect you, right, and that they are going to do justice. What happened had happened [sexual assault] and that couldn't be undone. I don't know how to explain it, like kind of a step towards healing, if that makes sense. Like that would have been my first step, instead it just kind of made a new pain to have to deal with.

When the police did not act, and investigate, the participants' expectations were broken. Before reporting, participants believed that the police response to their report would be taken more seriously. Participants described that they expected "I would get called back", "that the assault would be investigated" or "they would take my report". However, many said that they never heard back from police and that their concerns were never followed up. These broken expectations lead to adverse social health outcomes for participants when they perceived they were not being believed. This included loss of trust in the police and re-victimization by the police.

\section{Loss of trust.}

Many participants described a loss of trust in the police and the justice system after not being believed and/or their report not being followed-up. Much of the discussion regarding loss of trust was based on participants' perceptions that the police did not care about them as individuals or that the police had too many other things to deal with. This loss of trust lead women to feel that there was no point in seeking assistance from the police in other situations. "We will take care of each other, because they [police] don't care about us and...you know, they don't believe you anyways, so don't even bother. We will deal with our own stuff". Another participant who was sexually assaulted and reported the assault to the police following an exam at the hospital, described feeling interrogated by the police, with the police officer's initial question being "Did you just do it and regret it?" This experience lead to her lack of trust and subsequent protective instincts with her two young children, "I always tell my kids police are safe to go to, but there is still hesitation 
with that... I wouldn't discourage them from it, but I would rather have them come to me and then I'll help them if something ever happened".

The loss of trust in police impacted some women who experienced further violence or sexual assaults and did not make subsequent reports out of fear of not being believed by the police. An Indigenous participant who described feeling immense shame when the police did not believe that her sexual assault had occurred, described the impact of the police response on her subsequent experience with violence, "When I first got into my domestic, the relationship was violent, like I never called [the police], I never called anytime that I got hit. I never felt like they would believe me anyway". Similarly, despite being drugged during her sexual assault, and left "hogtied" on a street, a participant who perceived her involvement in the sex trade contributed to not being believed by the police, described the impact of the disbelief on her well-being, "Well, I was in a relationship where I was beat, beat very badly, and it took me 2 years before I reported it...because they wouldn't believe $m e$ ". Participants' prior experience with police greatly impacted their subsequent physical and mental health, as several described enduring subsequent abuse rather than making police reports.

\section{Re-victimization.}

Women had various motivations to report their sexual assaults to the police. Many of the women wanted to make a report to have the perpetrator charged, or to prevent others from being assaulted. Some described how they felt nervous to make the police report and only did so with encouragement from family, friends or healthcare/service providers. When the women did report, and were not believed, some felt re-victimized by the reporting experience and the questions they were asked. A young woman who was sexually assaulted after a social outing with friends on a University campus, described her interaction with the police as:

His [police officer] demeanour, like a bit of everything; his tone. I remember his tone because he was like well did you do this? Even the way he asked it was like, what were you wearing? ... That's the one thing I can really remember, and I said those questions shouldn't stick with me for the rest of my life, but they do. I feel like sometimes that was worse than the actual incident.

Similarly, another participant who survived through involvement in sex work, commented that the police response to her report was "well you work the streets, you bring it on yourself". Furthermore, the police officer stated, "serves you right for being out there on the corners and out at night, you women ask for it. I will never forget that; you women ask for it!" The experience of being let down by the professional who is supposed to protect you was perceived as emotionally damaging well beyond the trauma of the sexual assault. It is this disbelief from the police that left women feeling defeated, unsafe and unworthy of protection and support.

\section{Loss of Self}

All participants expressed that not being believed by police impacted them on a personal level. Many described how the disbelief from police impacted their well-being and made them feel as if a part of them had been lost or taken away. The women described feelings of loss regarding their self-worth, self-esteem, self-image, and/or self-confidence after not being believed. A woman who was drugged by her perpetrator, 
had a rape kit done at the hospital, reported the assault to the police and felt dismissed by them, discussed the impact of disbelief from the police on her sense of self,

It took away from who I was as a person before that, and it chipped away at my self-esteem. It made me think ok, well if these people think that I am not worthy of investigation and not worthy of fighting for, then why should I fight for myself? Why should I fight for my life?

Similarly, another participant who was sexually assaulted repeatedly by her step-brother, explained the impact that the disbelief from the police had on her self-worth, stating "You feel like if the police don't care what happens to you, why should l, right?" The internalization of the police response was articulated by one of the women, "I do the same thing that they did to me, I sweep me under the carpet". The words of participants portray how many of the women felt that the lack of investigation and validation of their report was synonymous with not being worthy or important enough. The lack of validation made one woman view herself as "a lying, drunk piece of shit really".

Women also described that not being believed impacted how they perceived themselves or how they were perceived by others. Women described that they felt "guilty", "like a liar", "like I did something wrong", "dismissed", "shame" and "angry" after not being believed. Some women described that they blamed themselves or felt guilty like it was their fault for going to the bar the night they were assaulted or that they willingly went with the individual who later assaulted them. Despite being the victims of crime, the interaction that women had with the police prompted an internalization of shame and personal responsibility for something outside of their control.

\section{Cumulative Effect}

Participants described how the sexual assault negatively impacted their health. All ( $n=23,100 \%)$ women experienced negative effects on their mental health including Post Traumatic Stress Disorder (PTSD), depression, and escalation or initiation of alcohol or drug abuse. Thirteen (57\%) had physical injuries (e.g., bruising, cuts, head injury) and many reported negative social effects including subsequent homelessness (n $=10,31 \%$ ) and/or future unreported assaults (sexual or physical) ( $n=17,74 \%)$. At times, it was difficult for the women to specifically separate out the effects of the sexual assault from those of not being believed on their health and well-being. However, participants described that not being believed exacerbated or added additional negative effects on their overall health and well-being. Many described that the experience of being sexually assaulted and then not being believed had a cumulative effect, which made the impact worse. One participant who was sexually assaulted in high school stated that,

I became very angry at the world that I had to go through that and nobody else did and or no one else even cared or believed me. It was a very dark place in my life. I tried to commit suicide after that too at one point. I had a lot of mental health issues.

Women used various descriptors in their interviews to explain how not being believed both had a significant effect and that this effect was long-lasting. In terms of the magnitude of the impact, one woman described that not being believed "probably affected me the worst". Another described how "it did have an effect on me 
emotionally, very strongly" and "you know I felt like that [emotional effects] for a very long time". Not being believed by police also meant that there would never be closure and this left women to wonder what could have been, or how their lives might have been different. A woman who experienced sexual assault from a distant family member explained the impact of the lack of closure "who would I be if these things never happened to me? Or maybe if the police believed me and there was closure to the case, would that make a big difference to me or would it not? I don't know." Similarly, a participant who found the courage to report a sexual assault that had been occurring in her home when she was away from her home environment in another community, had her file transferred numerous times without any police officer taking full responsibility. She explained how not being believed added to the sexual assault, "I think it's the whole thing, the big picture, the whole experience. You know, like why me? What did I do to deserve this?"

\section{Discussion}

This study aimed to explore the impact that being sexually assaulted and not believed by the police had on women's health. Overall, women described that not being believed by police had a negative impact on their mental (e.g., low self-esteem, self-worth, revictimization) and social health (e.g., loss of trust, experiencing and not reporting further assaults) beyond the impact of the sexual assault (e.g., PTSD, substance use, physical injuries etc.). This highlights that not being believed by police resulted in additional mental and social burdens during an already traumatic period. For many of the women, they perceived the impact to be both significant and long-lasting. These findings are noteworthy as they suggest women who were not believed by police felt re-victimized and may have suffered additional trauma. Our findings provide a unique contribution to the literature with women's first-hand accounts. Having a better understanding of their experience is an important step toward improving the response to sexual assault reports.

Our findings are consistent with the general sexual assault literature that suggests that women often feel revictimized from the lack of investigation, insensitivity, perceived judgment from officers, and low rates of arrests and sentencing of the perpetrator(s) (32). Unexpected negative reactions, including blame, judgment, disbelief, and lack of empathy may negatively influence well-being and recovery $(33,34)$. Negative social reactions to sexual assault disclosures may amplify feelings of powerlessness, grief, loss, and disenfranchisement $(7)$, shame $(35,36)$, increased severity and duration of PTSD (37) and other mental health concerns (38). When the sense of self (e.g., self-worth) is negative, there are often greater risk-taking behaviours as survivors may not feel that they are worthy of protecting or deserving of safety and wellness (37). The women in our study, who had negative reporting experiences, lost trust in police, described further assaults, victimization, and a delay in accessing services, among others. Without treatment, women felt that the negative effects of the sexual assault and not being believed were cumulative, severe and long lasting. Furthermore, many had poor mental health (e.g., PTSD, depression, anxiety) and reports of escalated substance use was frequently described as a coping mechanism.

Women's first-hand accounts of their reporting experiences from our study legitimize the associated trauma that presents when women's reports are not believed by police. In addition, as women were not believed they were not referred for support or treatment, leaving survivors to either attempt to heal from within, or turn to health and social service providers for support on their own. When women's sexual assault disclosures are 
responded to with empathy and validation, they experience less aversive health outcomes (39). In addition to improved health, women who have positive experiences are also more likely to utilize adaptive coping strategies (40) and are more likely to approach formal helping networks (41). Given the deleterious effects of not being believed by the police on the health and well-being of survivors, and the known benefits of an empathic response, health and social service professionals may be well positioned to assist women in rebuilding their lives, introducing positive coping strategies, and ensuring that women's voices matter.

Health and social service professionals may be able to reduce the impact of re-victimization (42) and the negative effect on health and well-being of survivors. Awareness of the experiences that sexual assault survivors have had with police is important for health and social service professionals to ensure that survivors are provided with a safe environment and their dignity is maintained. Person-centered care is central to the helping professions. Thus, providing compassionate care and preserving the dignity and well-being of the survivor (43) is essential to mitigating the impact of the assault and the experience of disbelief from the institutions designed to protect them. Comprehensive care for survivors is needed for immediate and longterm health benefits (44). Professionals are also well-equipped to fulfill an advocacy role with sexual assault survivors (27) which may assist in re-visiting the sexual assault report, safety planning, achieving justice through law enforcement, and subsequently assist in closure for survivors.

Our research has demonstrated that sexual assault survivors fear reporting subsequent victimization to the police due to a lack of trust in them. This is problematic as access to positive formal supports may mitigate the severity of trauma reactions among survivors (33). Health and social service professionals trained in trauma informed care may be able to increase sexual assault reporting by supporting survivors and advocating for sensitive treatment from the police. While numerous factors may impact women's recovery from the trauma of sexual assault (45), enhancing the disclosure experience is one strategy that may be beneficial to attain long-term health and wellbeing of survivors. Sexual assault is already one of the most under-reported crimes.

The lack of reporting of sexual assault is problematic for several reasons. First, underreporting of sexual assault minimizes the problem and falsely underestimates the number affected. Having an accurate recording of the extent of sexual violence is necessary for the allocation of services (46). Safety is also of concern, as recidivism of sexual perpetration is a risk for both the survivor and/or another individual(s). Furthermore, if women do not disclose the sexual assault, they may be more likely to suffer in silence and be at-risk for not receiving supportive services. Given that survivors of trauma often feel betrayed and may have difficulty trusting others (47), their reluctance to report is not surprising. Efforts are needed to provide a safe space for victims to disclose sexual violence without being further victimized (47).

\section{Implications for Practice and/or Policy}

The women in our study clearly articulated the negative impact that not being believed had on their well-being beyond the sexual assault. Their voices (e.g., research themes) need to be disseminated to provide a better understanding of women's experiences, which may lead to increased sexual assault reporting and an improved response from law enforcement. Education regarding women's experiences and how to respond

Page 10/16 
positively to survivors is required for community service providers, police, and healthcare professionals who receive sexual assault reports $(21,38,48)$. Sensitivity training for police officers that is inclusive of women's voices and experiences may also serve to reduce bias, and improve belief of survivors. This may be particularly important in smaller communities where there are no sexual assault specialized units. Strategies that survivors feel are helpful include providing time to talk about their experience (e.g., listening), conveying belief, telling them it is not their fault, and promoting agency (38). Minimizing blame, offering support, validating their experience, providing support and follow-up (37) and safety planning are also important for health and well-being (38). Furthermore, incorporating trauma-informed principles such as establishing safety, respect, choice, collaboration, and empowerment are additional strategies that could help facilitate a positive disclosure experience and minimize the possibility of re-traumatization (49). Using this type of approach recognizes the impact violence has had on individuals and attempts to minimize re-victimization (49). Finally, educational campaigns are required to challenge the normalization of rape culture myths, so that victims feel safe to report and/or seek services for sexual assault (50).

\section{Limitations}

Participation is the study was voluntary and limited to women who self-disclosed that their sexual assault report to police was not believed. We were unable to determine whether the cases were classified as unfounded by police. This study provides only the perspective of those who perceived that they were not believed and did not seek out those who reported sexual assault and had positive experiences. Lastly, the participants in this study were primarily women who reported low income and education residing in one geographic area and the findings may not be generalizable to all women.

\section{Conclusions}

Sexual assault has long been associated with adverse outcomes for survivors. Not being believed by police after reporting a sexual assault has an additional negative impact on survivors beyond that of the assault. Efforts are needed to improve the support for sexual assault disclosures for women so that they can report sexual assault without experiencing further victimization, thereby increasing their safety and potentially mitigating re-victimization. The women's voices from our study may provide police and health and social service providers with a better understanding of sexual assault survivors thereby improving police response.

\section{Abbreviations}

PTSD: post-traumatic stress disorder

AM: Ainsley Miller (author)

KM: Karen McQueen (author)

JM-O Jodie Murphy-Oikonen (author)

\section{Declarations}




\section{Ethics approval and consent to participate:}

was obtained by the Lakehead University Research Ethics Board (ref \# 1466856). Informed consent was obtained by all participants who participated in the research.

\section{Consent for publication:}

N/A

\section{Availability of data and materials:}

The voice recordings and transcription are stored by the Principle Investigator and are not available publicly due to the sensitive nature of the data and risk of breaching confidentiality.

\section{Competing interests:}

All authors disclose that they no competing interest (financial or otherwise) in the conduct of the research or the presentation of findings.

\section{Funding:}

This research was funded by SSHRC Insight Development Grant \#1466362. The role of the funder was to provide monies to cover the costs to conduct the research including research personnel (research assistants), transcription costs, travel and accommodations for interviews, participant honoraria, dissemination).

\section{Authors contributions:}

Each author has made a substantial contribution to the conception and implementation of the research study. J.M-O provided oversight on all aspects of the study from conception through to implementation. All authors participated in the interviewing of participants and reviewed all transcripts. KM, J.M-O and AM had overall responsibility of the data analysis with LC providing feedback on themes. All authors have participated in the writing of the manuscript and have reviewed the final submission.

\section{Acknowledgments:}

The authors would like to acknowledge Alexa Hiebert and her assistance with recruitment and interviewing.

References 
1. Benoit, C., Shumka, L., Phillips, R., Kennedy, M.C., \& Belle-Isle, L. Issue brief: Sexual Violence Against Women in Canada. [Internet]. Status of Women Canada.; 2016. Available from:

https://books.scholarsportal.info/uri/ebooks/ebooks0/gibson_cppc-chrc/2016-04-25/1/10049251

2. Smith, S., Chen, J., Basile, K., Gilber, L., Merrick, M., Patel, N., Walling, M. \& Jain, A. The National Intimate Partner and Sexual Violence Survey (NISVS): 2010-2012 State Report [Internet]. National Center for Injury Prevention and Control, Centers for Disease Control and Prevention; 2017. Available from: https://www.cdc.gov/violenceprevention/pdf/NISVS-StateReportBook.pdf

3. World Health Organization. World Report on Violence and Health [Internet]. Available from: https://apps.who.int/iris/bitstream/handle/10665/42495/9241545615_eng.pdf?sequence=1

4. Dworkin ER, Menon SV, Bystrynski J, Allen NE. Sexual assault victimization and psychopathology: A review and meta-analysis. Clin Psychol Rev. 2017 Aug1;56:65-81.

5. Ahrens CE. Being silenced: The impact of negative social reactions on the disclosure of rape. Am J Community Psychol. 2006 Dec1;38(3-4):263-74.

6. Badour CL, Feldner MT, Babson KA, Blumenthal H, Dutton CE. Disgust, mental contamination, and posttraumatic stress: Unique relations following sexual versus non-sexual assault. J Anxiety Disord. 2013 Jan;27(1):155-62.

7. Bordere T. Disenfranchisement and ambiguity in the face of loss: The suffocated grief of sexual assault survivors. Fam Relat. 2017 Feb;66(1):29-45.

8. Jozkowski KN, Sanders SA. Health and sexual outcomes of women who have experienced forced or coercive sex. Women Health. 2012;52(2):101-18.

9. Astbury J, Bruck D, Loxton D. Forced Sex: A critical factor in the sleep difficulties of young Australian women. Violence Vict. 2011;26(1):53.

10. Santaularia J, Johnson M, Hart L, Haskett L, Welsh E, Faseru B. Relationships between sexual violence and chronic disease: A cross-sectional study. BMC Public Health. 2014;14(1):868-82.

11. Wong JS, Balemba S. Resisting during sexual assault: A meta-analysis of the effects on injury. Aggress Violent Behav. 2016;28:1-11.

12. Shaw J, Campbell R, Cain D, Feeney H. Beyond surveys and scales: How rape myths manifest in sexual assault police records. Psychol Violence. 2017; 7(4):602.

13. Venema RM. Police officers' rape myth acceptance: Examining the role of officer characteristics, estimates of false reporting, and social desirability bias. Violence Vict. 2018;33(1):176-200.

14. O’Neal EN, Spohn C, Tellis K, White C. The truth behind the lies: The complex motivations for false allegations of sexual assault. Women Crim Justice. 2014;24(4):324-40.

15. Weiser DA 1. Confronting myths about sexual assault: A feminist analysis of the false report literature. Fam Relat. 2017;66(1):46-60.

16. Women's Law Project. Policy Brief: Advocacy to improve police response to sex crimes. [Internet]. 2013 [cited 2020 Aug 1]. Available from: https://www.womenslawproject.org/wpcontent/uploads/2017/06/Policy_Brief_Improving_Police_Response_to_Sexual_Assault_Feb2013_FINALrevd-2016.pdf 
17. Doolittle R, Pereira M, Blenkinsop L, Agilus J. Will the Police Believe You? A 20-month investigation by the Globe and Mail reveals that sexual-assault victims are more likely to be believed in some areas of the country than in others. Globe \& Mail. 2017;3.

18. Rotenberg, C. Police-reporter sexual assaults in Canada, 2009 to 2014: A statistical profile. Juristat: Canadian Centre for Justice Statistics. 2017.

19. Ferguson CE, Malouff JM. Assessing police classifications of sexual assault reports: A meta-analysis of false reporting rates. Arch Sex Behav. 2016;(5):1185.

20. Jordan J. Perfect victims, perfect policing? Improving rape complainant's experiences of police investigations. Public Adm. 2008;86(3):699-719.

21. Venema RM. Police officer schema of sexual assault reports: Real rape, ambiguous cases, and false reports. J Interpers Violence. 2016;(5):872.

22. Campbell R. The psychological impact of rape victims' experiences with the legal, medical, and mental health systems. Am Psychol. 2008;63(8):702-17.

23. Alderden MA, Ullman SE. Creating a more complete and current picture: Examining police and prosecutor decision-making when processing sexual assault cases. Violence Women. 2012;(5):525.

24. Chen Y, Ullman SE. Women's reporting of sexual and physical assaults to police in the national violence against women survey. Violence Women. 2010;16(3):262-79.

25. Patterson D. The linkage between secondary victimization by law enforcement and rape case outcomes. J Interpers Violence. 2011;26(2):328-47.

26. Greeson MR, Campbell R. Sexual assault response teams (SARTs): An empirical review of their effectiveness and challenges to successful implementation. Trauma Violence Abuse. 2013;14(2):83-95.

27. Chakaryan H. Effective ways to approach sexual assault response. Couns Today. 2018;61(1):52-7.

28. World Health Organization. Constitution [Internet]. 2020. Available from: Retrieved from: https://www.who.int/about/who-we-are/constitution

29. Van Manen M. Researching lived experience: Human science for an action sensitive pedagogy. Routledge; 2016 Jun 16.

30. Tong A, Sainsbury P, Craig J. Consolidated criteria for reporting qualitative research (COREQ): a 32-item checklist for interviews and focus groups. International journal for quality in health care. 2007 Dec $1 ; 19(6): 349-57$.

31. Colaizzi, P. Psychological research as the phenomenologist views it. In Valle \& Kings (eds), ExistentialPhenomenological Alternatives for Psychology. Oxford University Press; 1978.

32. Alderden M, Long L. Sexual assault victim participation in police investigations and prosecution. Violence Vict. 2016;31(5):819-36.

33. Campbell R, Dworkin E, Cabral G. An ecological model of the impact of sexual assault on women's mental health. Trauma Violence Abuse. 2009;10(3):225-46.

34. Mason F, Lodrick Z. 3: Psychological consequences of sexual assault. Best Pract Res Clin Obstet Gynaecol. 2013;27:27-37. 
35. Bhuptani PH, Kaufman JS, Messman-Moore TL, Gratz KL, DiLillo D. Rape disclosure and depression among community women: The mediating roles of shame and experiential avoidance. Violence Women. 2019;25(10):1226-42.

36. DeCou CR, Cole TT, Lynch SM, Wong MM, Matthews KC. Assault-related shame mediates the association between negative social reactions to disclosure of sexual assault and psychological distress. Psychol Trauma Theory Res Pract Policy. 2017;9(2):166-72.

37. Thompson KM. Helping survivors of sexual assault: J Am Acad Physician Assist. 2020;33(1):39-44.

38. Kirkner A, Lorenz K, Ullman SE. Recommendations for responding to survivors of sexual assault: A qualitative study of survivors and support providers. J Interpers Violence. 2017;088626051773928.

39. Quinn DM, Williams MK, Quintana F, Gaskins JL, Overstreet NM, Pishori A, et al. Examining effects of anticipated stigma, centrality, salience, internalization, and outness on psychological distress for people with concealable stigmatized identities. PLoS one 2014;9(5):e96977.

40. Ullman SE, Peter-Hagene L. Social reactions to sexual assault disclosure, coping, perceived control, and PTSD symptoms in sexual assault victims. J Community Psychol. 2014;42(4):495-508.

41. Campbell R. Pathways to Help: Adolescent Sexual Assault Victims' Disclosure and Help-Seeking Experiences. Violence Women. 2015;21(7):824-47.

42. Maier SL. Sexual assault nurse examiners' perceptions of the revictimization of rape victims. J Interpers Violence. 2012;27(2):287-315.

43. Campbell R, Greeson M, Patterson D. Defining the boundaries: How sexual assault nurse examiners (SANEs) balance patient care and law enforcement collaboration. J Forensic Nurs. 2011;7(1):17-26.

44. Abrahams N, Devries K, Watts C, Pallitto C, Petzold M, Shamu S, et al. Worldwide prevalence of nonpartner sexual violence: A systematic review. The Lancet. 2014;383(9929):1648-54.

45. Starzynski LL, Ullman SE. Correlates of perceived helpfulness of mental health professionals following disclosure of sexual assault. Violence Women. 2014;20(1):74-94.

46. Muldoon K, Smith G, Talarico R, Heimerl M, McLean C, Sampsel K, et al. A 15-year population-based investigation of sexual assault cases across the province of Ontario, Canada, 2002-2016. Am J Public Health. 2019;109(9):1280-7.

47. Cleary M, Hungerford $C$. Trauma-informed care and the research literature: How can the mental health nurse take the lead to support women who have survived sexual assault? Issues Ment Health Nurs. 2015;36(5):370-8.

48. Spohn C, Tellis K. The criminal justice system's response to sexual violence. Violence Women. 2012; (2):169.

49. Elliott DE, Bjelajac P, Fallot RD, Markoff LS, Reed BG. Trauma-informed or trauma-denied: Principles and implementation of trauma-informed services for women. J Community Psychol. 2005;33(4):461-77.

50. Eisenberg ME, Palacios L, Lust K, Porta CM. Sexual assault reporting and emotional distress among college female-identified victims/survivors: J Forensic Nurs. 2019;15(4):222-30.

\section{Supplementary Files}


This is a list of supplementary files associated with this preprint. Click to download.

- COREQchecklist.docx

- UnfoundedInterviewGuideSA.docx 